\title{
A TRAGICOMÉDIA ESPANHOLA COMO MODELO: A ÓPERA JOCO-SÉRIA DE ANTÔNIO JOSÉ DA SILVA COMO TENTATIVA DE SUPERAÇÃO
}

\author{
Carlos Junior Gontijo Rosa ${ }^{1}$
}

\begin{abstract}
RESUMO: O presente artigo busca analisar a influência que as preceptivas dramáticas do Século de Ouro espanhol exerceram sobre a produção teatral portuguesa do período. Para tal, recorremos a algumas peças do dramaturgo português Antônio José da Silva, O Precipício de Faetonte, Os Encantos de Medeia e Anfitrião, ou Júpiter e Alcmena, a fim de comprovar a hipótese de que o autor português, ao emular o modelo espanhol, acaba por vezes, superando-o em questões de forma e conteúdo.
\end{abstract}

PALAVRAS-CHAVE: Antônio José da Silva; Tragicomédia; Teatro Português; Teatro Espanhol; Século de Ouro Espanhol.

ABSTRACT: This paper seeks to analyse the influence of the Spanish Golden Age's dramatics preceptives had on the Portuguese theatral production of the period. To this end, we resort to $O$ Precipício de Faetonte, Os Encantos de Medeia and Anfitrião, ou Júpiter e Alcmena, by the Portuguese playwriter Antônio José da Silva, to prove the hypothesis that the author, to emulate the Spanish model, sometimes surpassing it in matters of form and content.

KEYWORDS: Antônio José da Silva; Tragicomedy; Portuguese Theater; Spanish Theater; Spanish Golden Age.

\section{Assi que, um, pela infâmia que arreceia, \\ E o outro, polas honras que pretende, \\ Debatem, e na perfia permanecem. \\ Luís de Camões. OS LUSÍADAS}

Os horizontes crítico, literário e historiográfico dos séculos XVI, XVII e XVIII, em virtude das tensas relações políticas entre Portugal e Espanha, motivam acaloradas discussões entre os intelectuais portugueses e espanhóis que se debruçam sobre o período. A esses textos críticos sobressai algum tipo de sentimento alheio à obra analisada. Tal como percebe a crítica italiana Luciana Stegagno Picchio, que a visão contra ou a favor da inserção do teatro espanhol em Portugal leva a atitudes de "rígido nacionalismo ou de aberto iberismo [e são] capazes em qualquer dos casos de influenciar num ou noutro sentido a apreciação estética das obras de arte" (PICCHIO, 1969, p. 157). Portanto, é preciso atentar às análises de questões até hoje tão

\footnotetext{
${ }^{1}$ Ator. Mestrando em Teoria e História Literária pelo Instituto de Estudos da Linguagem da Universidade Estadual de Campinas.
} 
apaixonadamente discutidas ${ }^{2}$.

O teatro português teve no século XVI seu maior dramaturgo: Gil Vicente (1465?-1536?). É perceptível, e pode ser visto em Brotherton (The 'Pastor-Bobo' in the Spanish theatre: before the time of Lope de Vega, 1975), que as figuras de seus textos dialogam com as leituras espanholas de tais tipos sociais e representações teatrais, como as de Juan de Encina, Fernando Díaz, Tirso de Molina, Torres Naharro dentre outros. Além disto, Gil Vicente escreveu parte de sua obra em castelhano. Da mesma maneira, a escola vicentina ultrapassa as fronteiras portuguesas e influencia Lope de Vega e sucessores. Inserindo-se, assim, na tradição espanhola, repercutirá no Século de Ouro do teatro castelhano que, por sua vez, retornará a Portugal.

Apesar de condoídos pela ausência de um teatro nacional português nos séculos em questão, acusar o teatro espanhol do Século de Ouro de obstruir o crescimento de um possível movimento do teatro nacional português é um argumento insustentável, principalmente se observarmos o extenso diálogo que se descreve nas artes cênicas do período.

Teria havido, durante parte dos séculos XVI e XVII, "uma espanholização da cultura lusitana na época da monarquia filipina nas ordens política, social e cultural." ${ }^{\prime 3}$ (DONOSO y PEÑA, 1992, p. 62). Não se nega que a política dos reis espanhóis possa ter afetado o pensamento português a tal ponto que fez morrer-lhe um sentimento nacional. No entanto, Portugal revolta-se contra Castilha e retoma a sua autonomia política através da guerra de Restauração, assinando tratado de paz em 1668.

Culturalmente, e especialmente no Teatro, a Espanha apresentou uma forte influência em toda a Europa. De modo semelhante, no século XVIII a ópera italiana virá influenciar fortemente os movimentos artísticos europeus, sendo que Portugal não só envia artistas para aprender na Itália - caso exemplar é o Padre Antônio Teixeira, que musicou as obras de Antônio José da Silva, e que foi por duas vezes estudar na Itália por conta da Coroa - como também importa artistas para Lisboa. Sendo assim, não podemos deixar de notar certo amargor dos críticos posteriores:

\footnotetext{
${ }^{2}$ Nas falas transcritas nas Atas do $1^{\circ}$ (e único) Congresso Luso-Espanhol de Teatro (1992), percebe-se nitidamente uma exacerbação das emoções dos falantes ao defender ou acusar seus países. Mesmo num espaço tido como tentativa de reunião amistosa e de aproximação, observa-se uma inconsciente animosidade entre as partes. Tentamos aqui manter-nos alheios ao discurso sem embasamento, dado que estamos em posição privilegiada, pois apresentamos um discurso distanciado de ambos, não recorrendo a formas de linguagem como "nosso" ou "deles", por exemplo.

${ }^{3}$ Tradução nossa, bem como nas demais citações de textos teóricos em outras línguas.
} 
Esta é a maior razão, estar escrito em sua maior parte em castelhano e ser imitação do teatro espanhol, pela qual o teatro português daquele século [XVII-XVIII] não só está sem estudos, como é criticado como coisa prejudicial e é condenado ao ostracismo. A verdade é que, com prejuízos nacionalistas, que não existem quando se trata de influências francesas, não se pode fazer história. Como é possível que em um período de tão pobre criação dramática, se desdenhe do pouco que se possui? (MONTES, 1992, p. 52, [grifo nosso]).

As peças do Século de Ouro espanhol chegam com força em Portugal a partir da anexação do seu território aos domínios do Rei Felipe II de Espanha - Felipe I de Portugal, em 1561, encontrando um teatro português acanhado e praticado de modo amador. "Deve-se imaginar a surpresa e o deslumbramento de um público que saía de uns primitivos autos para as complexas tramas de uma comédia de Lope de Vega, recitada pelos mais famosos comediantes espanhóis da época" (MONTES, 1992, p. 51).

Mesmo não se identificando com os conceitos filosóficos muito arraigados de Espanha, o público português se entretinha e compreendia os enredos espanhóis. Mas as comédias espanholas, dado este novo mercado consumidor, transportou para seus enredos também os mitos, histórias e personagens portugueses.

Aos portugueses, elogiava-se seu valor, cortesia e engenho, bem como a beleza, honestidade e firmeza das mulheres, mas censurava-se com brincadeiras, que raramente ultrapassava as fronteiras do bom gosto, a mania fidalguista, a arrogância, a vaidade e, sobretudo, a condição enamorada (MONTES, 1992, p. 51).

Ainda de acordo com Montes (1992, p. 49), o teatro espanhol influencia os palcos e autores portugueses não só nos aspectos temáticos, mas também nos aspectos técnicos e linguísticos. Linguisticamente, no século XVI, através principalmente da utilização dos sayagués e sua adaptação à língua portuguesa.

O sayagués é a principal característica do personagem-tipo que Brotherton (1975) chama de pastor-bobo, ancestral do gracioso espanhol. Constitui-se como um dialeto do espanhol, de conotação rústica e simples, diferenciando-se do falar culto e letrado daqueles personagens sapientes, a exemplo do dialeto bolonhês do Arlecchino na Commedia dell'Arte.

Tecnicamente, nos séculos XVII e XVIII, o teatro segue as preceptivas de um gênero novo, desenvolvido em Espanha, a tragicomédia. Tal gênero foi referenciado pela primeira vez por Juan de La Cueva em 1606.

Si destas soledades te importunas, y ya huyendo quieres desviarte 
de las montañas, prados y lagunas,

dellas, si gustas, quiero acompañarte al cómico teatro, adonde veas la fábula ingeniosa recitarte.

Dirás que ni la quieres ni deseas, que no son las comedias que hacemos con las que te entretienes y recreas. [...]

Que es en nosotros un perpetuo vicio jamás en ellas observar las leyes ni en persona, ni en tiempo, ni en oficio.

Que en cualquier popular comedia hay reyes, $\mathrm{y}$ entre los reyes el sayal grosero con la misma igualdad que entre los bueyes.

A mí me culpan de que fui el primero que reyes y deidades di al tablado, de las comedias traspasado el fuero.

(Juan de La Cueva, Epístola III, Ejemplar poético (1606). In: ESCRIBANO y MAYO, 1965, p. 115) ${ }^{4}$.

A tragicomédia começa a tomar as proporções que teria no século XVII e parte do XVIII apenas no Arte Nuevo de Hacer Comedias en Este Tiempo, escrito em 1609, por Lope de Vega à Academia de Letras de Madrid. O Arte Nuevo defende que a comédia não deveria ser menosprezada como gênero inferior à tragédia, mas apenas tida como gênero que fala de temas cotidianos. Esse pensamento já era difundido na Espanha quinhentista e pode ser visto em preceptistas como Lopéz Pinciano e outros (ESCRIBANO y MAIO, 1965).

Em verdade, a tragicomédia já é descrita em textos romanos, como o Anfitrião, de Plauto, mas só no século XVII será reconhecida como gênero dramático, assistida, apreciada e escrita por poetas de talento e posição na corte.

O que eu vou fazer é que seja uma peça mista, uma tragicomédia, porque me não parece adequado que tenha um tom contínuo de comédia a peça em que aparecem reis e deuses. E então, como também entra nela um escravo, farei que seja, como já disse, uma tragicomédia (PLAUTO, Anfitrião, p. 36).

De acordo com Patrice Pavis (2008, p. 420), a tragicomédia é uma "peça que participa ao mesmo tempo da tragédia e da comédia" e "se define pelos três critérios do tragicômico (personagem, ação, estilo)". Por personagens, podemos

\footnotetext{
${ }^{4}$ Texto mantido no original, em espanhol, para evidenciar a linguagem poética em que foi escrito o tratado.
} 
entender que são tipos pertencentes tanto à classe popular quanto à aristocracia e nobreza, deixando de lado a divisão aristotélica, em que "divergem a tragédia e a comédia; esta os quer [aos personagens] imitar inferiores e àquela superiores aos da atualidade." (ARISTÓTELES, II, 3).

Quanto à ação tragicômica, pode ser "séria e até mesmo dramática, [mas] não desemboca numa catástrofe e o herói não perece" (PAVIS, 2008, p. 420). Assim que, como podemos perceber nos textos de Lope de Vega, Calderón de La Barca, outros autores contemporâneos e especialmente de Antônio José, a ação da peça conduz a um final terrível, mas dá uma guinada no último momento, conduzindo a uma reviravolta feliz, ou ao menos pretensamente feliz.

Ao estilo estão ligadas as noções de "alto" e "baixo", no que concerne à linguagem utilizada pelas personagens. Numa tragicomédia, deve-se apresentar tanto a linguagem elevada dos personagens nobres quanto o linguajar cotidiano e rasteiro dos personagens cômicos e servis, como se pode ver na cena a seguir, na qual Chichisbéu tenta enganar Fíton e Faetonte (Precipício, p. 116):

Chichisbéu: Faetonte disse?! Ai, que ali está meu amo! Pois, por vida minha, hei-de magicar com ele.

$[\ldots]$

Fíton: Senhor, agora reparo! Aquele é o meu livro e o meu vestido! Este homem deve ser algum velhaco.

Faetonte: Assim me parece. Já sei que és um fingido ignorante.

Chichisbéu: Sabes mais do que eu.

Fiton: Quem te deu esse livro?

Chichibéu: Ninguém, porque o achei.

Faetonte: Pois como insolente me pretendias enganar?

Chichisbéu: Venha cá! Tão louquinho está, que me não conhece? Não vê que sou Chichisbéu?

Por fim, Pavis (2008, p. 420) afirma que a tragicomédia "se preocupa com o espetacular, com o surpreendente, com o heroico, com o patético", fato que não podemos deixar de notar, em se tratando do mito de Faetonte, da incursão na peça da carruagem do Sol, assim como as descrições de bosques, selvas, caçadas e outros cenários e cenas que prendem a atenção do público pelo que David Ball chama de teatralidade. "Alguma coisa é teatral quando intensifica a atenção e o envolvimento dos espectadores" (BALL, 2008, p. 59).

Em El hijo del Sol, Faetón, Calderón de La Barca tem todos os elementos que caracterizam uma tragicomédia dispostos ao longo da peça. Possui personagens que 
representam as diversas classes, desde o rei Admeto, as ninfas Tétis, Galatea e Amaltea, os heróis Faetonte e Épafo-Peleu e os subalternos Bastillo e Silvia, sendo que todos apresentam linguagem condizente com sua condição. A reviravolta final ou desenlace termina em final feliz, com a recuperação da honra de Tétis e as bodas da ninfa com Peleu. Mas Faetonte continua morto.

Antônio José resolve sua peça de maneira mais adequada aos critérios tragicômicos e também tem todos os elementos que caracterizam uma tragicomédia dispostos ao longo da peça, mas em O Precipício de Faetonte compõe um enredo completamente diferente de El hijo del Sol, Faetón. O Judeu pode não ter sido influenciado diretamente pela peça calderoniana, mas é certo que as características das preceptivas do século XVII espanhol são marcantes na obra do autor lusitano. Já foi dito por Curtius (1996) que o Século de Ouro espanhol não foi influenciado pelas preceptivas aristotélicas. Sendo isso verdade ou não, o fato é que, diferentemente dos franceses, que engessaram seus textos em possíveis unidades comentadas pelo estagirita (e também partindo de suas próprias teorias), os autores espanhóis constroem uma nova forma teatral. Usando inserções cômicas e trágicas ao longo da peça, a tragicomédia se mostra um gênero ágil, de grande aceitação nas mais diversas camadas sociais ibéricas.

Importante lembrar que Calderón de La Barca, na sua peça, traz a relação binária não apenas para o conteúdo (verdade/mentira), mas também para sua forma. Os cômicos são cômicos e os trágicos são trágicos. O hibridismo esquemático do teatro espanhol, no qual os enredos cômicos e trágicos dividem a cena, mas não se mesclam, é levado às últimas consequências na peça portuguesa, com uma grande permeabilidade entre os gêneros. Bom exemplo é quando, na cena 2 da Parte 2, Faetonte é acertado por uma flecha de Ismene. Ela pergunta da ferida física, enquanto este divaga sobre a ferida da paixão que ela lhe causou no peito. Chegam Albano, Mecenas, Fíton e Chichisbéu. Albano diz que Faetonte é o traidor, por informações que teve na cena anterior, enquanto Chichisbéu diz que ele é filho do Sol. Embora seja verdade, aqui é dito como um plano mentiroso para que Faetonte case-se com Ismene. Enfim, uma grande situação dramática, na qual várias situações anteriores têm seu desdobramento, resolução ou aperto do nó ${ }^{5}$. Mais interessante é que, dentre todos os personagens envolvidos na cena,

\footnotetext{
${ }^{5}$ Situação dramática, segundo Patrice Pavis (2008, p. 363) é o "conjunto de dados textuais e cênicos indispensáveis à compreensão do texto e da ação, em um determinado momento da leitura ou do espetáculo. [...] Descrever a situação de uma peça equivale a tirar, num momento preciso, uma fotografia
} 
apenas Chichisbéu é gracioso. Os outros seriam trágicos, mas inseridos numa situação de quiproquó, tipicamente cômica.

Em O Precipício de Faetonte, mais do que nas outras obras do Judeu, os personagens são desvirtuados de suas posições costumeiras. O protagonista, Faetonte, tenta matar a amada, usa de recursos escusos para se casar com ela, quase alcançando seu intento. A corrupção se espalha por todos os personagens e situações da peça. A morte de Faetonte é apenas o final de todo um emaranhado de vícios. Fíton já avisava, no final da Parte 2, que tudo levaria ao precipício. Assim, a intervenção de Apolo ao reviver Faetonte soa artificial e não convence o público. É um final feliz, mas que não faz esquecer todas as ações "desviadas" de Faetonte.

Evidente que o efeito produzido é um tipo de estranhamento para o público, habituado às comédias de capa-e-espada espanholas. As personagens são apresentadas, trágicas e cômicas, mas transitam entre as funções formais ao longo da peça. Assim como Fíton e Chichisbéu trocam de papel, também estruturalmente a peça ora se mascara, ora se revela. Esta vertiginosidade da ação pode ser descrita como um labirinto circular, termo cunhado por Pierre Furter (1964) e que metaforiza as estruturas de suas peças, nas quais as personagens são jogadas. A cada quiproquóo, elas são lançadas mais fundo no labirinto, e mesmo as mais potentes magias e engenhosidades não as farão escapar do seu destino. A obra do Judeu mostra, assim, segundo Furter, um traço pessimista, pois a salvação e a alegria são recursos exteriores às situações das peças, que tendem a um final catastrófico. A boa aceitação do público, comprovada em escritos sobre o autor, pode vir de um "golpe de teatro". Todo chacoalhar do entendimento do público é encerrado no fim com um final feliz, aliás uma verdadeira inversão do mito ovidiano.

A partir destes poucos comentários, podemos perceber que Antônio José, fazendo parte de uma tradição teatral, usa seu estro para desenvolver peças que atraiam a atenção do público. Tudo em Antônio José é graça e diversão. Se há algum outro tipo de preocupação, ela fica em segundo plano, pois que suas peças terminam bem. Final feliz que deixa uma sensação amarga no público.

Para um estudo sobre dramaturgia que busca abranger aos aspectos tanto

de todas as relações das personagens". Para o espectador, a situação dramática é necessária como "ponto de apoio relativamente estável sobre cujo fundo os pontos de vista variados e cambiantes se destacam como que por contraste" (PAVIS, 2008, p. 364). 
literários quanto cênicos de uma obra teatral representada em data tão distante quanto às óperas de Antônio José, resta buscar elementos no próprio texto que evidenciem a relação deste com a cena propriamente dita. Nesse intuito, vem em nosso auxílio o livro Texto e representación en el teatro del Siglo de Oro (1997), editado por Aurelio González. Nele, vários autores discutem a questão da dupla textualidade nas obras do teatro áureo espanhol. Entende-se por dupla textualidade a relação entre o texto literário, ou seja, a publicação da obra como chegou até nós, e o texto espetacular, que são as indicações, diretas ou indiretas, presentes na obra e que dizem respeito à mise-en-scène. Tais indicações podem aparecer em formas de didascálias, apartes ou comentários feitos entre as personagens e permitem uma análise dos movimentos cênicos das obras.

Na dramaturgia do Século de Ouro espanhol, e também no teatro português de Antônio José da Silva, não há a utilização de um personagem-narrador. Sendo assim, do que o personagem fala de si, do que os outros personagens falam dele e de suas ações é que podemos tirar conclusões sobre ele (GONZÁLEZ, 1997; CANDIDO, 2007). Uma vez que estes elementos podem ser convergentes ou contraditórios, eles conferem tensão dramática à obra - e, por vezes, profundidade psicológica, quando aplicável. Podemos recolher essas informações da parte textual, do texto literário.

Por outra parte, o personagem, para ser efetivamente dramático, não pode limitar sua vitalidade ao texto literário, mas deve poder desenvolver-se no texto espetacular que implica à montagem da obra. Portanto, deve ter a capacidade de ser representado no cenário, habitualmente por um ator, o qual levará elementos de figurino e adereços que sublinhem ou façam explícita a caracterização exigida pelo texto literário. (GONZÁLEZ, 1997, p. 12).

Além desta parte textual, e com as mesmas funções de conferir profundidade psicológica, estão os elementos sonoros e visuais, ou seja, músicas, figurinos e cenário. São chamados de significação de segundo grau e trazem a ambientação da peça, mas com a superação da significação que têm na vida cotidiana. O texto espetacular só alcança o texto literário quando lhe é conferido um nível de significação equiparável, o cotidiano tornado signo. Em O Precipício de Faetonte, um grande elemento de conflito entre as personagens são a capa e o livro de Fíton que Chichisbéu acha. Sua descrição pode ser apreendida nas falas de ambos os personagens, além do que Mecenas reconhece Chichisbéu como Fíton através dos trajes.

(sai Fíton com um livro na mão, que ao depois o lançará no chão, e se despe)

Fíton: Aonde achará refúgio um infeliz? Depojar-me quero desta 
recopilada ciência, que, inútil, me não ampara; e, para que mais disfarçado possa escapar deste bárbaro furor, será preciso mudar de traje. (Precipício, p. 102).

[...]

Chichisbéu: Mas que é isto que ali está? Ora vejamos. Oh! É um vestido que está despido. Ora sabia Deus que já este meu estava por um fio. Se me chegará? Vejamos. Belo! Justamente! Alguma alma algebibista se compadeceu da minha piranguice. Olá! Temos mais um livro?! Não há dúvida: é livro! E é de razão que o veja. Ora bem dizem que em Itália nascem os livros, como nascem as malvas! Vejamos se achamos nele alguma cousa, pois dizem que tudo se acha nos livros. (Assenta-se e começa a folhear o livro). Abramos e vejamos o que contém. Liber astrolomágico. Irra! Mágico! Passa fora! Vejam lá que matéria peçonhenta contém o tal livrinho! Libera me! Ora ainda assim, salva a consciência, vamos vendo o Index rerum notabilium. Capítulo primeiro, de fisionomia, quod est narigorum confrontatio. Isto há-de ser galante. Capítulo segundo, de Nigromantia. Isto é cousa de negros. Negra ciência é esta! Eu não quero ver mais, que se me vão arrepiando os cabelos. (Precipício, p. 104).

[...]

Mecenas: Este que vês, Senhor, é o nigromântico Fíton, que junto às margens do Erídano o achámos, e segundo as confrontações do traje tessálico e este livro de mágica com caracteres gregos, que na mão tem, me persuade ser o próprio que buscamos. (Precipício, p. 108).

Podemos perceber nas duas didascálias presentes nos trechos citados a indicação de ações claras que os personagens deverão realizar para continuação do enredo. Mas também podemos observar, especialmente na fala de Chichisbéu, algumas ações que não carecem de didascálias, pertencendo ao campo do ator a execução destas. Está explícito, por exemplo, que Chichisbéu veste o traje encontrado e ainda avalia como “Belo! Justamente!”. Por estas e por outras, não se pode perder de vista que o espetáculo teatral é uma obra artística de várias mãos - dramaturgo, diretor, atores, público.

As didascálias influenciam e são influenciadas pela visão que o dramaturgo tem do seu texto em cena, enquanto ambientação ou sugestão de símbolos e signos cênicos. Numa época em que a função do encenador ainda não existia, as indicações do dramaturgo são importantes para o entendimento da ação cênica. Antônio José não se apoia tanto no texto espetacular justamente por lidar com bonecos. Ou, por outra, ele usa o texto espetacular de forma diferente justamente por escrever para bonifrates. $\mathrm{O}$ texto literário que remete ao espetacular está na boca dos criados, especialmente aquele texto que dá as intenções dos personagens de cortiça. Exemplar é a primeira cena da peça Os Encantos de Medeia (1735), na qual Jason, numa conferência com o Rei Etas, 
encanta-se por sua filha Medeia e mente ao Rei. Estas informações são dadas pelo criado Sacatrapo, em aparte:

Este rei Etas já tem bastante idade; é o Aetas, aetatis. E Jason como se está espinicando todo diante de Medeia! E mais ele, que é tuna nos ossos!

$[\ldots]$

Arre lá, como mente tão airoso, e nas bochechas de um rei!

(Encantos, p. 13).

Ainda deve-se apontar a uma movimentação bastante audaciosa do Judeu na cenografia desta obra. Já vimos em Medeia a vinda do carro do Sol, bem como também será visto no Faetonte. Vimos os labirintos de Creta se materializando e monstros como o Minotauro e o dragão de Colcos. Antônio José usa de um recurso de maquinaria espetacular em diversas de suas obras. Sem desprezar o carro do Sol ou o raio que o atravessa na peça, vamos prender nossa atenção na cena 2 da Parte 2, quando Fíton faz com que se movam as árvores da selva de uma parte para outra. Este espetacular recurso de maquinaria, assim como o nariz de Chichisbéu crescer - talvez só possível realmente em um teatro de bonifrates -, adquire também significado simbólico, enquanto texto espetacular.

A partir das tópicas retóricas que caracterizavam a elaboração textual até meados do século XVIII, podemos entender que Antônio José emula as formas dramáticas pregressas, provenientes de Espanha, buscando e por vezes alcançando a superação do modelo.

Sobre o efeito de permeabilidade, buscado pela representação, entre o espaço dos atores e dos espectadores, deve-se recordar que uma das tópicas características do período é entender o mundo como teatro, a vida como posta em cena. A tópica não só informa textos literários, como vale de cosmovisão. Assim, qui se emprega o recurso do espetacular para equiparar as condições dos dois espaços: verossímil e verdadeiro, ambos sujeitos ao aparente e, portanto, ao desengaño (LEAL, 1997, p. 108).

Nas peças de Antônio José da Silva, verdadeiro e verossímil trocam de lugar. As personagens acreditam naquilo que querem, pois o labirinto é muito profundo e o julgamento dos homens é falho (Furter, 1964). Os caracteres que têm mais força, como Mecenas e o Rei Tages, escolhem a verdade que querem. Já caracteres mais fracos, como Chichisbéu, rendem-se às imposições de lugares que não são os seus. É sempre a busca da "verdade" mais fácil que leva aos quiproquós das peças. Esta relação de poder está presente mesmo entre Anfitrião e Júpiter, em Anfitrião ou Júpiter e Alcmena, 
quando todos acreditam em Júpiter e prendem Anfitrião, ou quando Saramago deixa de acreditar que seja Saramago, porque Mercúrio diz que é Saramago.

\section{REFERÊNCIAS}

ARISTÓTELES. A Poética Clássica. Tradução de Jaime Bruna. São Paulo: Cultrix, 2005.

BALL, David. Para trás e para frente: um guia para leitura de peças teatrais (1983). Tradução de Leila Coury. São Paulo: Perspectiva, 2008.

BROTHERTON, John. The 'Pastor-Bobo' in the Spanish theatre: before the time of Lope de Vega. London: Tamesis Books, 1975.

CALDERON DE LA BARCA, Pedro. El hijo del Sol: Faetón (1662). Alicante: Biblioteca Virtual Miguel de Cervantes, 2001.

CANDIDO, Antonio et al. A personagem de ficcção. São Paulo: Perspectiva, 2007.

CONGRESSO LUSO-ESPANHOL DE TEATRO, I. "Presenças e ausências nas relações teatrais luso-espanholas”. Dramaturgia e Espetáculo: Actas. Coimbra, 23 a 26 de setembro de 1987. Coimbra: Livraria Minerva, 1992, p. 45-103.

CURTIUS, Ernst Robert. Literatura européia e Idade Média latina. Tradução de Teodoro Cabral e Paulo Rónai. São Paulo : Hucitec/ EDUSP, 1996.

DONOSO, Piedad Bolaños; PEÑA, Mercedes de los Reyes. "El teatro español en Portugal (1580-1775): estado de la cuestión". In: CONGRESSO LUSO-ESPANHOL DE TEATRO, I. Dramaturgia e Espetáculo: Actas. Coimbra, 23 a 26 de setembro de 1987. Coimbra: Livraria Minerva, 1992.

ESCRIBANO, Federico Sánchez e MAYO, Alberto Porqueras. Preceptiva dramática española. Madrid: Editorial Gredos, 1965.

FURTER, P. "La structure de l'univers dramatique d'A. J. da Silva, 'o Judeu"”. Bulletin des Etudes Portugais, n. s., n. 25, 1964, p. 51-75.

GONZÁLEZ, Aurelio. "Caracterización de personajes en el teatro cervantino". In: Texto e representación en el teatro del Siglo de Oro. México: El Colegio del México, Centro de Estudios Lingüísticos y Literarios, 1997.

GONZÁLEZ, Aurelio. Texto e representación en el teatro del Siglo de Oro. México: El Colegio del México, Centro de Estudios Lingüísticos y Literarios, 1997. 
LEAL, Gabriela. "El mágico prodigioso: la representación barroca como epifanía”. In: GONZÁLEZ, Aurelio (ed.). Texto y representación en el teatro del Siglo de Oro. México: El Colegio de México, Centro de Estudos Lingüísticos y Literarios, 1997.

MONTES, José Ares. "Bodas y divorcio del teatro hispano-portugués". In: CONGRESSO LUSO-ESPANHOL DE TEATRO, I. Dramaturgia e Espetáculo: Actas. Coimbra, 23 a 26 de setembro de 1987. Coimbra: Livraria Minerva, 1992.

PAVIS, Patrice. Dicionário de teatro Tradução de Jacó Guinsburg e M. Lúcia Pereira. São Paulo: Perspectiva, 2008.

PICCHIO, Luciana Stegagno. História do Teatro Português. Tradução de Manuel de Lucena. Lisboa: Portugália, 1969.

PLAUTO. Anfitrião. Tradução de Agostinho da Silva. Porto Alegre: Globo, 1952.

SILVA, Antônio José. Obras completas. Prefácio de José Pereira Tavares. Lisboa: Sá da Costa, 1957-1958. 4 volumes. Volume 2: Anfitrião, ou Júpiter e Alcmena e Os Encantos de Medeia; Volume 4: O Precipício de Faetonte.

VEGA, Lope de. Arte nuevo de hacer comedias (1609). Madrid: Cátedra, 2006. 